\title{
A Case Study for Evaluation of GUTD on Soil Compaction and Tractor Performance
}

\author{
Saadat Kamgar ${ }^{1} \&$ Ehsan Savand Roomi ${ }^{2}$ \\ ${ }^{1}$ Department of Biosystems Engineering, College of Agriculture, Shiraz University, Shiraz, Iran \\ Correspondence: Ehsan Savand Roomi, Department of Biosystems Engineering, College of Agriculture, Shiraz \\ University, Shiraz, Iran. E-mail: savandroomi59@gmail.com
}

\author{
Received: November 10, 2015 Accepted: December 15, 2015 Online Published: January 15, 2016 \\ doi:10.5539/jas.v8n2p130 URL: http://dx.doi.org/10.5539/jas.v8n2p130
}

\begin{abstract}
Machinery traffic on farm and forest caused to problems in environment and economics by Fossil fuel consumption and soil compaction. According to result of investigation, The GUTD (Gear Up and Throttle Down) method was recommended to decrease fuel consumption. But the wide range of machinery applications, soil conditions and experience of drivers or operators need to have index for ensuring the GUTD method is carried out properly. The purpose of this study was evaluation of GUTD method using MF 399 tractor on instantaneous fuel consumption and soil compaction. The tractor was equipped by sensors, a designed electronic circuit and a computer to measure and record parameters such as fuel consumption, forward speed and wheel slip. This field examination was carried out on tilled land with clay-loam soil and then data were analyzed in a randomized complete block design with three replications. Considered factors were included four speed levels (1.6, 3.2, 6.4, $12.8 \mathrm{~km} \cdot \mathrm{h}^{-1}$ ), three levels of gear (first, second and third) and two levels of wheel drive (2WD and 4WD). Parameters of cone index and bulk density were used to determine soil compaction.Variations in compaction of before and after tractor passage were calculated in each plot. Statistical analysis in each speed showed that factor of gear in variations of soil compaction was significant at all speeds except $12.8 \mathrm{~km} \cdot \mathrm{h}^{-1}$ and instantaneous fuel consumption was reduced by GUTD at each of constant speed except the mentioned speed. This research showed that instantaneous fuel consumption can be considered as appropriate index for selecting the best gear and speed in terms of fuel consumption and soil compaction.
\end{abstract}

Keywords: fuel consumption, forward speed, gear ratio, MF 399 tractor

\section{Introduction}

Agriculture tractors are designed for different conditions in one season farm work. Increasing number of powerful tractors on farm causes to use them sometimes in light works. In cases where operation is required to be less than $75 \%$ of total power of tractor (light works), fuel consumption can be considerably reduced by performing GUTD. A number of researchers have studied the GUTD technique as a solution to proportionate load on tractor in field operations to consume fuels more economically. Tewari and Mondal (2011) evaluated GUTD by a digital fuel economizer (DFE) system in laboratory and field experiments conditions and concluded that in laboratory tests fuel consuming decrease from 7.1 to $15.8 \%$ in different load conditions. Field experiment with two bottom mould board plough showed maximum 2.6 to $15.8 \%$ fuel saving for different depths of operation. Experiments showed that with full load condition scope of DFE is very limited. Lister (1985) performed GUTD on 16 tractors in a limited amount of load which fuel consuming decrease fairly from 9 to $18 \%$. Grogan et al. (1987) developed an instrumented tractor with an on-board microcomputer to measure engine load, engine speed, wheel slip, fuel consumption, draught, and hitch forces. The analysis indicated that farmers could have reduced fuel consumption up to $15-27 \%$ by practicing "shift-up, throttle-back"; i.e. by shifting to a higher transmission gear and reducing the engine speed to maintain a nearly constant forward travel speed. Actual fuel consumption dropped in the range of (from) 20 to $11.3 \%$, in controlled field tests.

Whether performing GUTD under any condition results less fuel consumption? With respect to continuous variation in soil, desirable performing of GUTD is difficult. Here there is a need to determine an index to assess the performance. On the other hand there are many older model tractors and even the majority of new models in developing countries, especially Iran that those were not equipped by precision measuring instruments such as slip meter, fuel meter, etc. Moreover majority of them are equipped by manual transmission (gearbox). Generally 
the cost of a system is an important factor for using it.

In result an index was requirement that it was measured by a simple and inexpensive technique. The study was performed with the hypothesis that the instantaneous fuel consumption of tractor reacts against improper operating conditions.

In this study, instantaneous fuel consumption for MF399 tractor pulling a trialer in different speeds and gears is investigated. Moreover, in respect to importance of soil compaction on crop yield, effect of GUTD on soil compaction was evaluated.

\section{Materials and Methods}

In this study two terms are considered: tractor action (instantaneous fuel consumption and wheel slip vs. purposeful changes such as gear ratios and forward speed) and soil reaction vs. tractor wheels.

\subsection{Experimental Site}

The experiments were done in a field with $18000 \mathrm{~m}^{2}$ area in Badjgah Research Station (northwest of Shiraz, Fars province, Iran), a view and map of the area were exhibited by Figures 1 and 2. Soil texture of the area was clayloam (35\% sand, $30 \%$ silt and $35 \%$ clay) and its plastic limit moisture was $27 \%$ out of dry weight. The climate of the area is warm and dry, the weather of testing days was sunny (early of the fall). The tests were performed about 25 days after maize harvesting. Before starting test, the field was tilled by a chisel plow followed by a roller, until $30 \mathrm{~cm}$ depth. Soil average moisture in $0-10 \mathrm{~cm}$ and $10-30 \mathrm{~cm}$ depth were found 0.4 and 0.6 of plastic limit of the field soil, respectively.

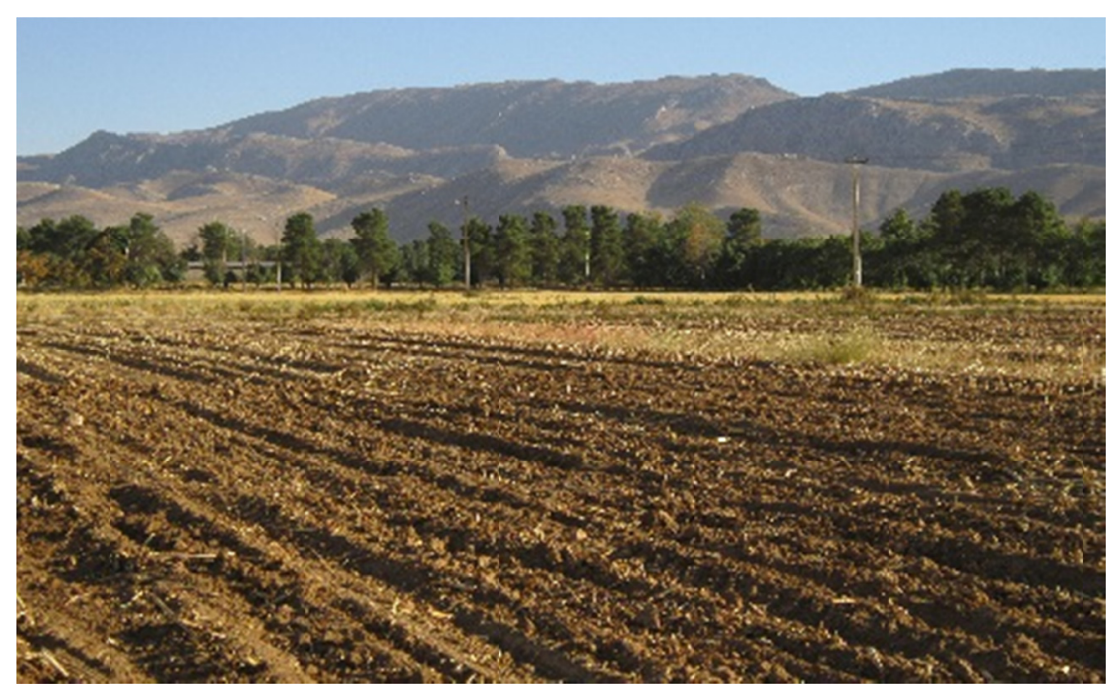

Figure 1. A view of experimental field 


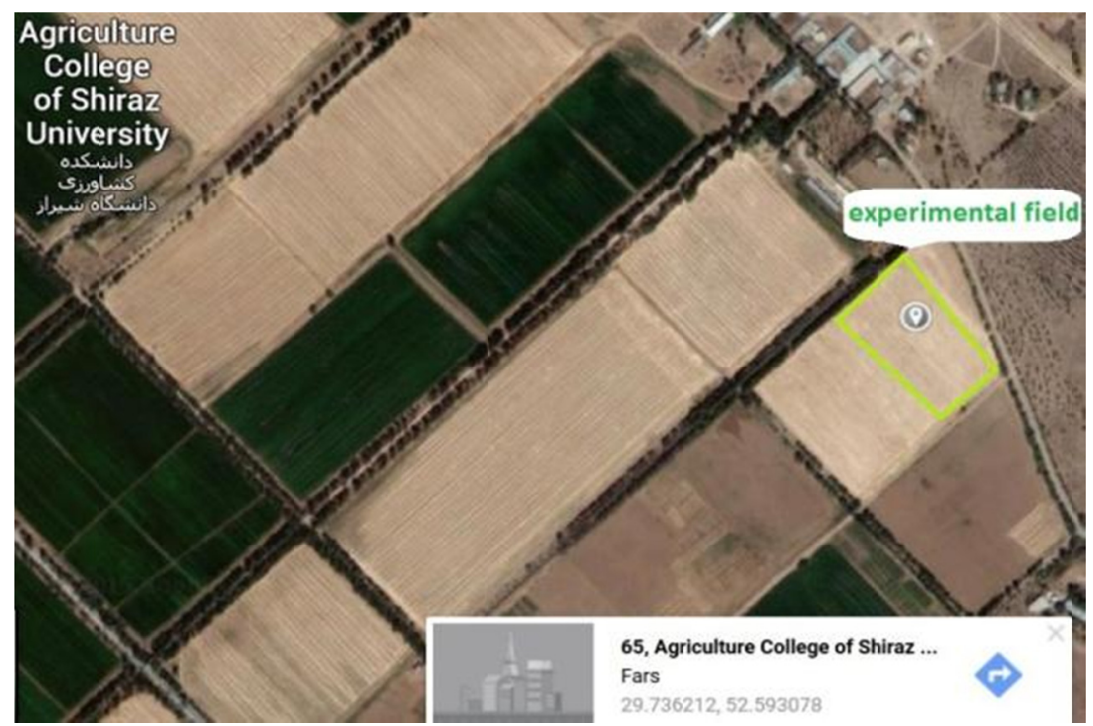

Figure 2. Satellite map and Accurate coordinates of the experimental field

\subsection{Tractor}

A Front Wheel Assist tractor, MF399 tractor (Figure 3) was used with the specifications in Table 1, which pulled a trailer with $1400 \mathrm{~kg}$ weight as offset (right trailer wheel did not pass on tractor wheel trace), it also was equipped by data acquisition system (Karparvarfard \& Rahmanian-Koushkaki, 2015; Raheman et al., 2007; Pranava et al., 2010; Singh et al., 2011).

Table 1. Technical specification of MF 399 tractor

\begin{tabular}{ll}
\hline Rated Engine Power $(2200 \mathrm{rpm})$ & $110 \mathrm{hp}$ \\
Max P.T.O. Power & $95 \mathrm{hp}$ \\
Total weight & $4000 \mathrm{~kg}$ \\
Transmission & Synchromesh, 12 forward, 4 revers Manual change \\
Front tire size & $14.9-24$ \\
Rear tire size & $18.4-34$ \\
\hline
\end{tabular}




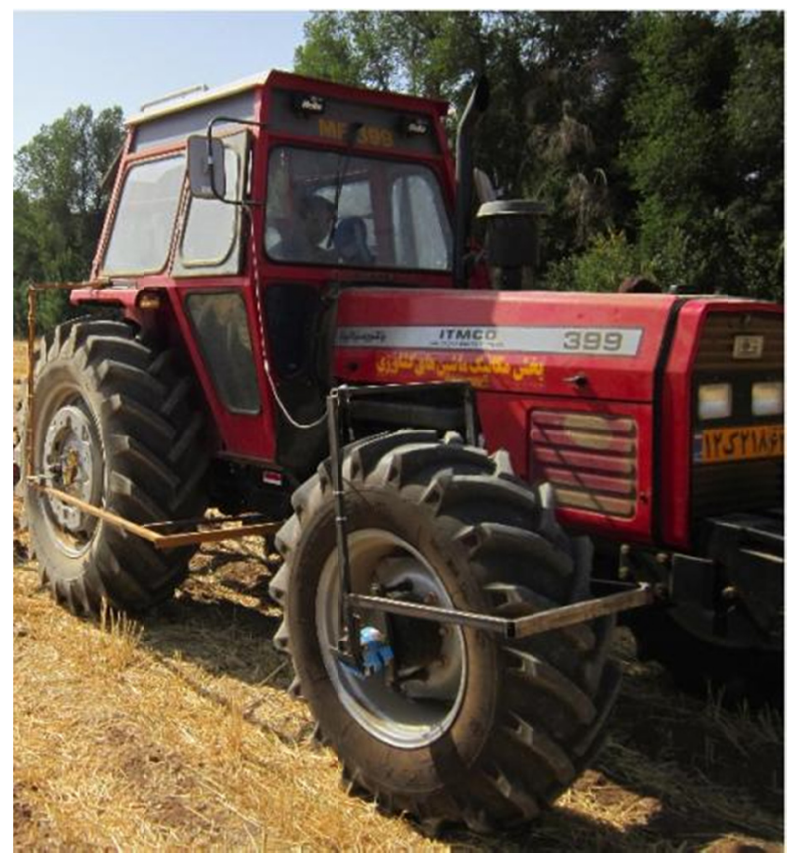

Figure 3. MF399 tractor

\subsection{Data Acquisition System}

An instrumentation package for measuring the tractor performance was developed. This package included the data acquisition system and the transducers for measuring fuel consumption, actual forward speed and slip. Specifications of the transducers used in the package are listed in Table 2. The data acquisition system consisted of an electronic board and a portable computer linked together via a USB port (Figure 4). Data were sampled at $0.1 \mathrm{~s}$ intervals. Three shaft encoders (Autonics, South Korea) with 500 pulse/revolution were used in this study (Figure 5). The actual forward speed was measured by using a fifth wheel (trailer wheel was used as fifth wheel), while the theoretical forward speed came from the right rear and front wheels for calculating slip percentage of them by Equation (1) (Pranav et al., 2010).

$$
S=\left(1-\frac{V_{a}}{V_{t}}\right) \times 100
$$

Fuel consumption was measured with two turbine flow transducers (VISION-1000, Switzerland) having a range of 0.1-2.5 L/min. One transducer was accommodated between the fuel filter and the injector pump, another transducer was used before the fuel tank to measure the fuel returning from both injectors and injection pump (Figure 6). The transducers data were inputted into a microcontroller to calculate the forward speed, wheel slip and instantaneous fuel consumption then digital and graphic output were displayed by Graphical user interface on monitor of laptop (Figure 7).

Table 2. Transducers and specifications

\begin{tabular}{llll}
\hline Name of the transducer & Specification & Made in country & Application \\
\hline Vision-1000, Turbine flow & $0.1-2.5 \mathrm{~L} / \mathrm{min}(22000$ pulse/L) & Switzerland & Measurement of fuel consumption \\
Autonics, Shaft encoder & 500 pulse/revolution & South Korea & $\begin{array}{l}\text { Measurement of actual forward speed } \\
\text { and theoretical forward speed }\end{array}$ \\
\end{tabular}




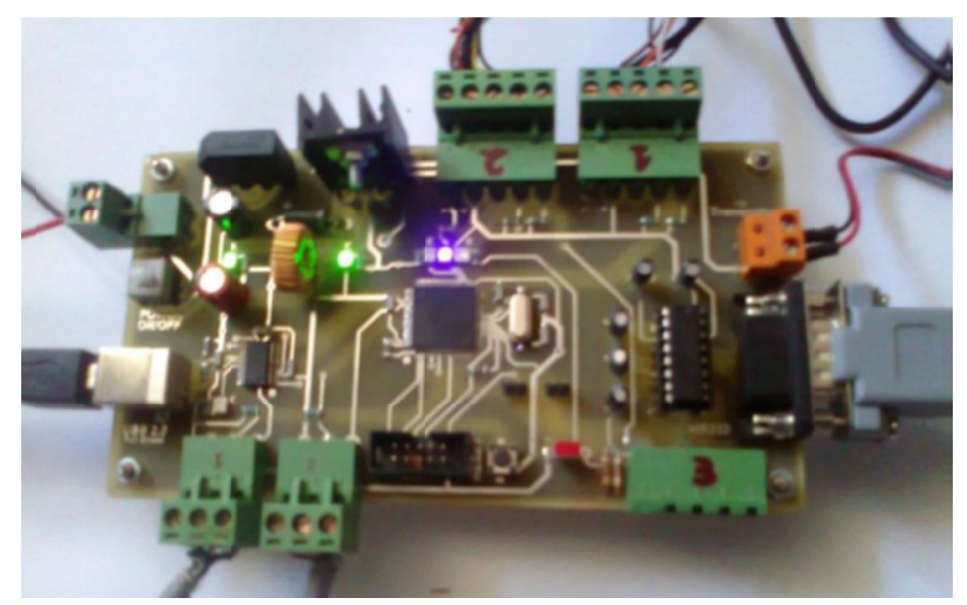

Figure 4. Data acquisition system

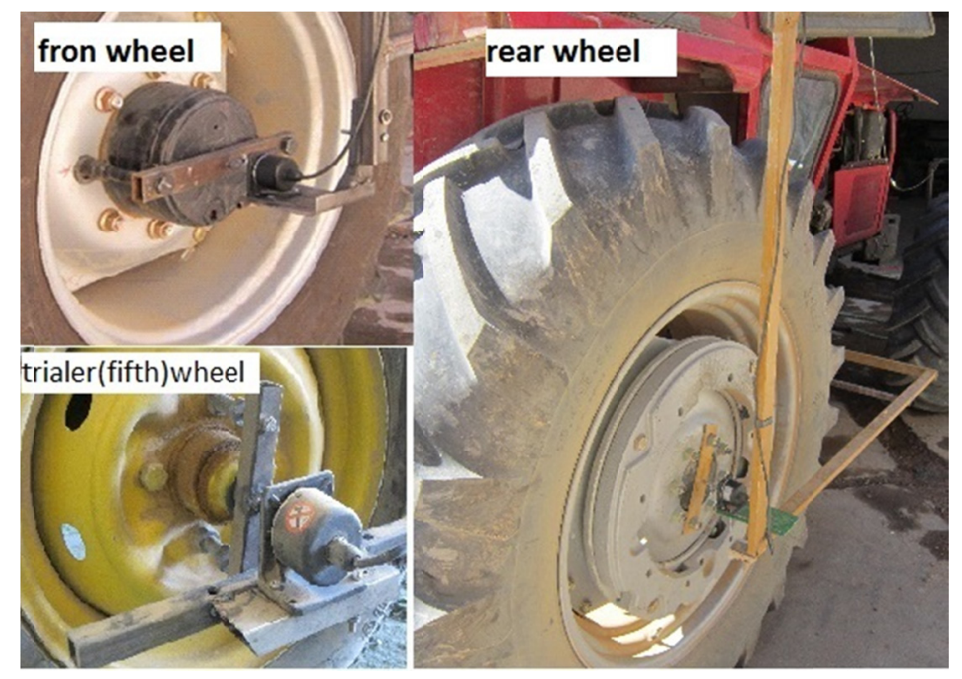

Figure 5. Location of encoders on tractor

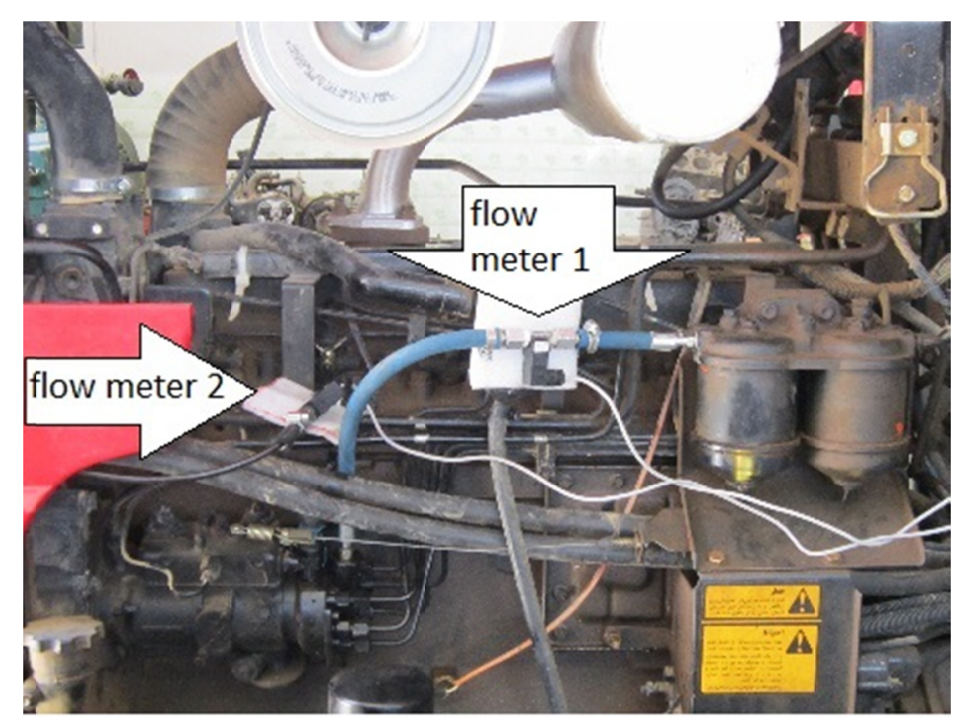

Figure 6. Location of flow meter on engine of tractor 


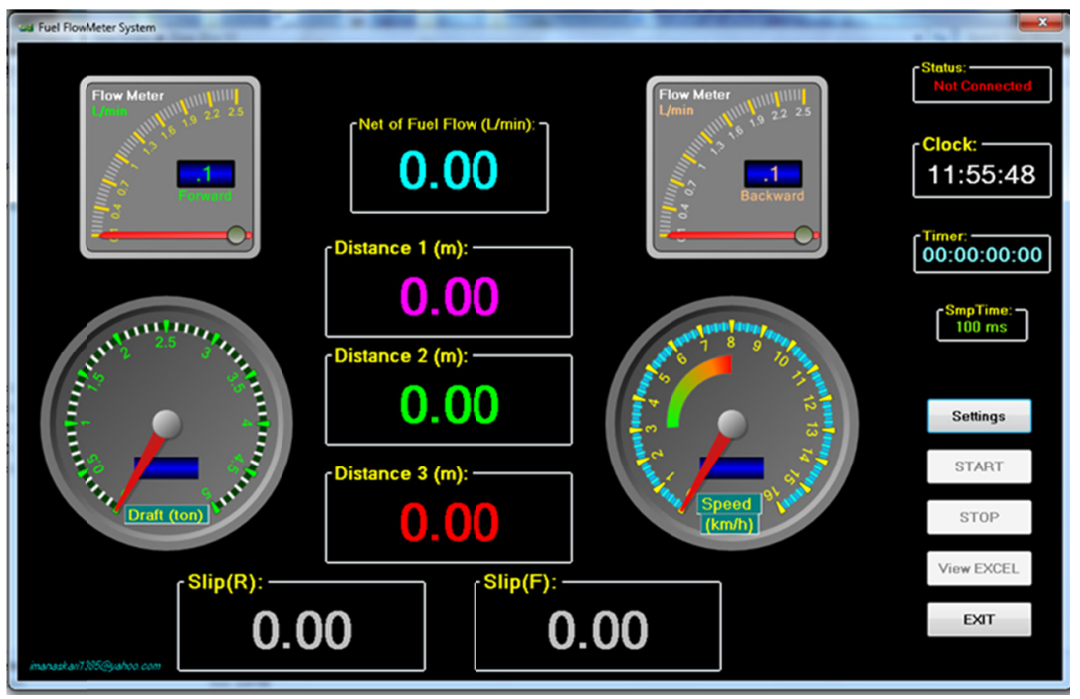

Figure 7. Graphical user interface

\subsection{Soil}

In this experiment, soil compaction as the reaction between soil and the tractor wheels was measured. To determine soil compaction, soil bulk density (BD) and soil penetration resistance were used.

\subsubsection{Soil Bulk Density (BD)}

BD which is one of the important soil compaction index was measured in 3 depths: $0-10 \mathrm{~cm}, 10-20 \mathrm{~cm}$ and 20-30 cm. Samples were taken before passage and after passage. Locations of sampling for after passage were exactly chosen at points that tractor was passed at determined speed.

BD was measured by undisturbed core sample. To minimize soil compaction by core sample, a cylinder of 70 $\mathrm{mm}$ inner diameter and $60 \mathrm{~mm}$ height with sharp edge was applied (Campbell, 2001).

After sampling, they were weighed by a digital Weighing Balance (with 0.001 gr. resolution) and were dried by a digital oven for 24 hours in $105^{\circ} \mathrm{C}$ and then weighed again and $\mathrm{BD}$ was determined by fllowing Equation (2).

$$
\rho=M / V
$$

Where, $\rho$ is $\mathrm{BD}$ of soil on gram per $\mathrm{cm}^{3}$, $\mathrm{M}$ is dry soil sample mass on gram and $\mathrm{V}$ is soil sample cylinder volume on $\mathrm{cm}^{3}$.

\subsubsection{Soil Penetration Resistance (PR)}

PR was determined by cone index (CI). To measure Cone index, an electrical penetrometer (model SP1000, Findlay Irvine, Scotland) was used. By applying ASAE 313.2 DEC94 standard related to penetrometer, sampling was done in two surface $(0-6 \mathrm{~cm})$ and undersurface $(6-12 \mathrm{~cm})$ depths that moisture was uniform. CI changes before and after passage, were evaluated in each plot to determine variations in soil compaction in each depth of surface and undersurface.

\subsection{Statistical Analysis}

A field experiment was done by a completely randomized block design factorial test in three replications. In evaluating soil compaction changes and MF 399 tractor performance (wheel slip and fuel consumption), the treatments were include: 4 speeds $(1.6,3.2,6.4$ and $12.8 \mathrm{~km}$ ); gear in 3 levels (first, second and third) and two levels wheel drive (2WD and 4WD), (e.g.: 4 speeds $\times 3$ gears $\times 2$ wheel drives $=24$ experimental cases $\times 3$ replications $=72$ tests). Moreover their effect on bulk density at three depths $(0-10,10-20$ and 20-30 cm) and on $\mathrm{CI}$ at surface and undersurface depths were evaluated. Sampling of centerline of tire track was performed exactly in places where tractor reached to specified speed.

The Tractor was operated at 12 forward gears in different forward speeds in the range of engine speed from 1200 to $2200 \mathrm{rpm}$, which three gear levels called first, second and third, were used in every forward speed (Table 3).

In the first gear, engine speed was $1950 \pm 50 \mathrm{rpm}$ and the second and third gear, engine speeds were: $1450 \pm 50$ and $1250 \pm 50$ rpm respectively. 
Evaluation and analysis of data was performed with analysis of variance (ANOVA) and Duncan test by SPSS.

Table 3. Matching tractor gears with named gears (first, second, third) in each speed $\left(\mathrm{km} \cdot \mathrm{h}^{-1}\right)$

\begin{tabular}{llll}
\hline Forward speed & First gear & Second gear & Third gear \\
\hline 1.6 & $1^{*}$ & 2 & 3 \\
3.2 & 4 & 5 & 6 \\
6.4 & 7 & 8 & 9 \\
12.8 & 10 & 11 & 12
\end{tabular}

Note. * Forward gear numbers (gear 1 to 12 ).

\section{Results and Discussion}

\subsection{GUTD Effect on Soil Compaction}

Soil compaction was investigated by two parameters, CI and BD.

\subsubsection{Changes}

CI changes were analyzed in four speeds separately. According to ANOVA results, gear effect was significant at the 0.01 level in all speeds except $12.8 \mathrm{~km} \cdot \mathrm{h}^{-1}$. The drive wheel effect was considerable at the 0.01 level, CI changes at $4 \mathrm{WD}$ were more than $2 \mathrm{WD}$ but this difference decreased by increasing speed. Depth effect was significant in $1.6 \mathrm{~km} \cdot \mathrm{h}^{-1}$ and at the 0.05 level while it was at the 0.01 level for other speeds and CI changes in undersurface depth was higher than surface. Comparison test (by Duncan test) between mean of CI changes at three gears in each speed was also performed (Table 4).

Table 3 shows that the effect of GUTD on soil compaction is related to forward travel speed because the variation process in compaction varies in each speed along with increasing such that in speed of 1.6 and 3.2 $\mathrm{km} \cdot \mathrm{h}^{-1}$, soil compaction in third gear is significantly less than first and second gears. But this reduction in 6.4 $\mathrm{km} \cdot \mathrm{h}^{-1}$ between third gear and first gear is not significant. Finally, in $12.8 \mathrm{~km} \cdot \mathrm{h}^{-1}$ on the contrary, compaction in third gear is more than first. Although it is not considerable but variation process in this speed varies with other ones.

Wheel slip was around 5 to $15 \%$ at all of speeds except of in speed of $12.8 \mathrm{~km} \cdot \mathrm{h}^{-1}$ at third gear, it reached to more than $20 \%$. In $20 \%$ Wheel slip, soil surface remained without changes but soil undersurface was compacted more than twice. High slippage can be a reason for changing in variation process of soil compaction in $12.8 \mathrm{~km} \cdot \mathrm{h}^{-1}$ in respect to other speeds. By considering Table 3, in terms of compactness, speed of $6.4 \mathrm{~km} \cdot \mathrm{h}^{-1}$ at the third gear was more suitable for drawbar force of the test among the tested speeds.

Table 4. Comparison test results of CI changes in GUTD method

\begin{tabular}{llll}
\hline \multirow{2}{*}{ Forward speed $\left(\mathrm{km} \cdot \mathrm{h}^{-1}\right)$} & \multicolumn{3}{c}{ Average CI changes after passage to before passage } \\
\cline { 2 - 4 } & First gear & Second gear & Third gear \\
\hline 1.6 & $2.18 \mathrm{~b}^{*}$ & $2.84 \mathrm{a}$ & $1.68 \mathrm{c}$ \\
3.2 & $2.09 \mathrm{a}$ & $2.02 \mathrm{a}$ & $1.59 \mathrm{~b}$ \\
6.4 & $1.65 \mathrm{~b}$ & $1.99 \mathrm{a}$ & $1.45 \mathrm{~b}$ \\
12.8 & $1.57 \mathrm{~b}$ & $1.82 \mathrm{a}$ & $1.64 \mathrm{~b}$ \\
\hline
\end{tabular}

Note. *Average values followed by the same letter and in the same row do not differ by Duncan's test: $\mathrm{P}<0.05$.

\subsubsection{BD}

BD was measured in 3 depths and ANOVA of BD variations (after passage than before passage) was done in each speed at three gears (first, second and third). This analysis showed that gear and drive wheel effect at three first speed in 0.01 level and in $12.8 \mathrm{~km} \cdot \mathrm{h}^{-1}$ but in 0.05 level were significant. Depth effect in all speeds was significant in 0.01 level, as compaction in second depth $(10-20 \mathrm{~cm})$ was more than compaction in first and third depths. 
Comparison test (by Duncan test) between mean of BD changes was performed at three gears in each speed (Table 5). The results show that in each constant speed, BD changes for third gear in $0-30 \mathrm{~cm}$ depth range was considerably lower than the first and second gear in all speeds except $12.8 \mathrm{~km} \cdot \mathrm{h}^{-1}$.

Regarding to Tables 4 and 5, in terms of compactness, speed of $6.4 \mathrm{~km} \cdot \mathrm{h}^{-1}$ at the third gear and $12.8 \mathrm{~km} \cdot \mathrm{h}^{-1}$ at the first gear are suitable for drawbar force of the test.

Table 5. Comparison test result of soil BD changes in GUTD method

\begin{tabular}{|c|c|c|c|c|}
\hline \multirow{2}{*}{ Forward speed } & \multirow{2}{*}{ Wheel drive } & \multicolumn{3}{|c|}{ Average comparison of soil BD changes based on gear change } \\
\hline & & First gear & Second gear & Third gear \\
\hline \multirow[t]{3}{*}{1.6} & 2WD & $1.28 \mathrm{a}^{*}$ & $1.29 \mathrm{a}$ & $1.22 b$ \\
\hline & 4WD & $1.39 \mathrm{a}$ & $1.41 \mathrm{a}$ & $1.32 b$ \\
\hline & Average & $1.33 \mathrm{a}$ & $1.35 \mathrm{a}$ & $1.27 \mathrm{~b}$ \\
\hline \multirow[t]{3}{*}{3.2} & 2WD & $1.23 \mathrm{a}$ & $1.24 \mathrm{a}$ & $1.20 \mathrm{~b}$ \\
\hline & 4WD & $1.35 \mathrm{a}$ & $1.33 \mathrm{a}$ & $1.23 \mathrm{~b}$ \\
\hline & Average & $1.29 \mathrm{a}$ & $1.28 \mathrm{a}$ & $1.22 \mathrm{~b}$ \\
\hline \multirow[t]{3}{*}{6.4} & 2WD & $1.18 \mathrm{a}$ & $1.18 \mathrm{a}$ & $1.11 \mathrm{~b}$ \\
\hline & $4 \mathrm{WD}$ & $1.23 \mathrm{~b}$ & $1.28 \mathrm{a}$ & $1.19 \mathrm{c}$ \\
\hline & Average & $1.21 \mathrm{a}$ & $1.23 \mathrm{a}$ & $1.15 b$ \\
\hline \multirow[t]{3}{*}{12.8} & $2 \mathrm{WD}$ & $1.13 \mathrm{a}$ & $1.12 \mathrm{a}$ & $1.12 \mathrm{a}$ \\
\hline & $4 \mathrm{WD}$ & $1.1 \mathrm{~b}$ & $1.18 \mathrm{a}$ & $1.24 \mathrm{a}$ \\
\hline & Average & $1.12 b$ & $1.15 \mathrm{ab}$ & $1.18 \mathrm{a}$ \\
\hline
\end{tabular}

Note. *Average values followed by the same letter and in the same row do not differ by Duncan's test: $\mathrm{P}<0.05$.

\subsection{GUTD Effect on Instantaneous Fuel Consumption}

Instantaneous fuel consumption (IFC) vs. forward gears was illustrated at 24 states (four speeds * three gears * $(2 \mathrm{WD} / 4 \mathrm{WD})$ ) by Figures 8 and 9, where each solid line in figures shows constant speed at three gears (carry out GUTD method). As it can be seen in the figures two points are worth attention.

$>\quad$ There are two consumption zones: first zone is in 3 first speeds, IFC is in 0.3 to 0.4 liter per $\mathrm{minute}^{\left(\mathrm{L} \cdot \mathrm{min}^{-1}\right)}$ and second zone is in $12.8 \mathrm{~km} \cdot \mathrm{h}^{-1}$ that increase to $0.46-0.53 \mathrm{~L} \cdot \mathrm{min}^{-1}$ ( 40 percent more than first zone).

$>\quad$ In three first speeds, when gear up, IFC decreases but in speed of $12.8 \mathrm{~km} \cdot \mathrm{h}^{-1}$ there is not decreasing process.

IFC has the sharp rise at $12.8 \mathrm{~km} \cdot \mathrm{h}^{-1}$ because some heavy implements, such as a single axle trailer, can exert excessive force on the drawbar. Force increases considerably with speed or on irregular terrain. So the force was exerted by the trailer to the tractor was more than producing tractor power therefor IFC was reaction to unfit exerted force. Tractor engine was lugging (black smoke existed from exhaust) in $12.8 \mathrm{~km} \cdot \mathrm{h}^{-1}$ at third gear (tractor gear: 12) while began to run but it was in normal position for the rest of the experiment. 


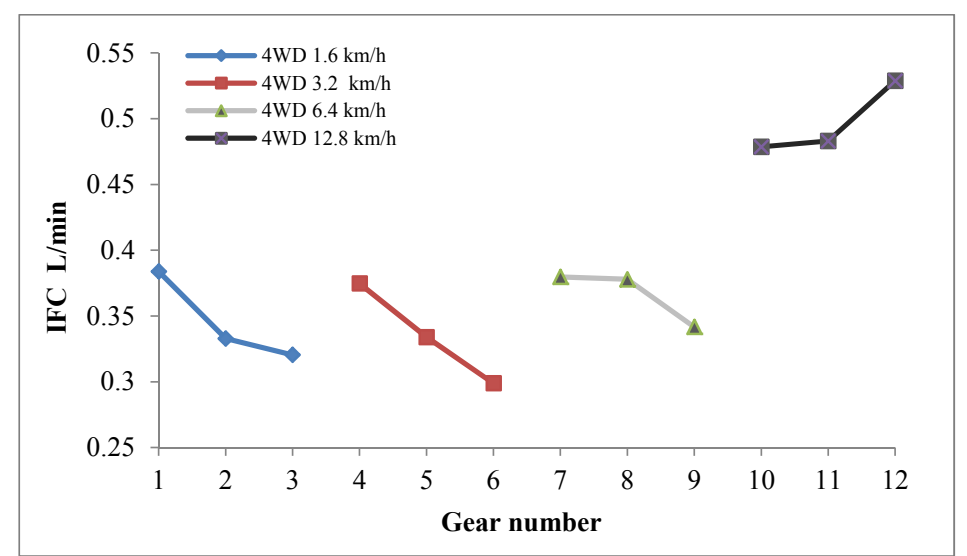

Figure 8. Tractor IFC in determined speeds at different gears in 4WD

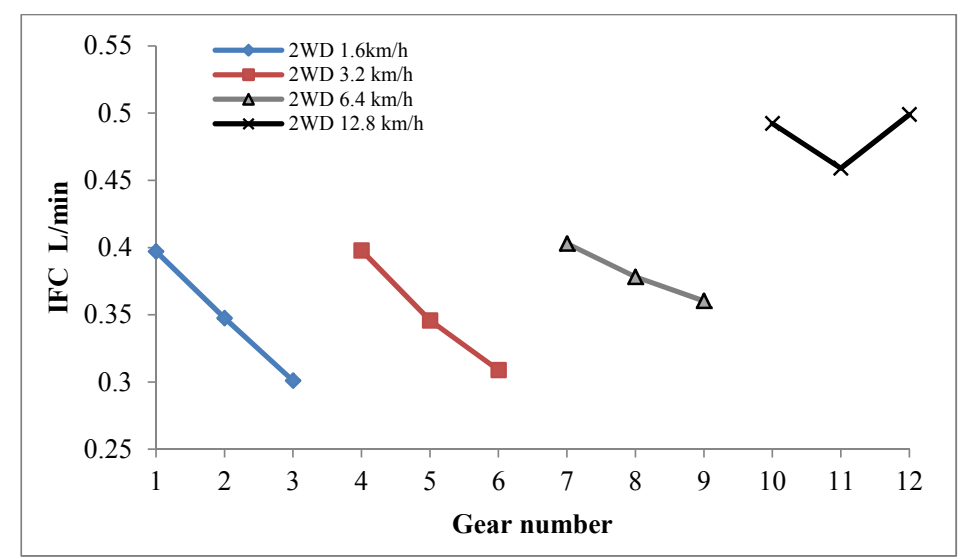

Figure 9. Tractor IFC in determined speeds at different gears in 2WD

\subsection{GUTD Effect on Fuel Consumption in 1000 Meters}

To better understand the fuel saving, IFC converted to fuel consumption (FC) for 1000 meters direct distance (Figure 10).

Figure 10 shows that GUTD method in $1.6 \mathrm{~km} \cdot \mathrm{h}^{-1}$ causes to save nearly 3 liters per 1000 meters (in 2WD more than $3 \mathrm{~L}$ and in $4 \mathrm{WD}$ less than $3 \mathrm{~L}$ ), in $3.2 \mathrm{~km} \cdot \mathrm{h}^{-1}: \mathrm{FC}$ reduction is about $1.5 \mathrm{~L}$ and in $6.4 \mathrm{~km} \cdot \mathrm{h}^{-1}$ it decreases around $0.4 \mathrm{~L}$, but in $12.8 \mathrm{~km} \cdot \mathrm{h}^{-1}, \mathrm{FC}$ was increased more than $0.2 \mathrm{~L}$.

As it can be seen in Figure 10, effect on FC by GUTD method is related to travel speed, other hand its effect reduce by increasing forward speed. Therefore the result of prior studies was confirmed (full load condition scope of DFE is very limited (Tewari \& Mondal, 2011)). 


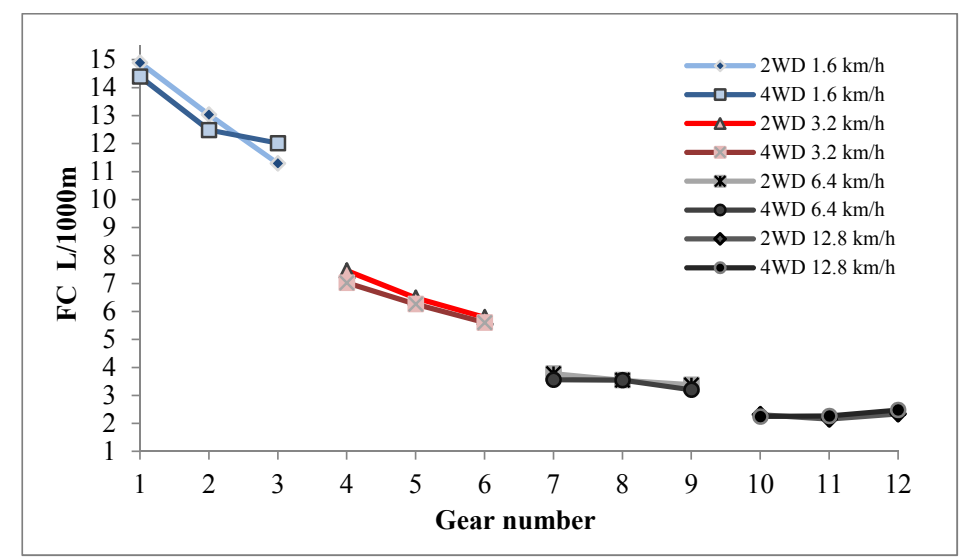

Figure 10. GUTD effect on Fuel consumption per 1000 meter in determined speeds at 2WD and 4WD

Finally based on soil compaction and instantaneous fuel consumption (IFC), speed of $6.4 \mathrm{~km} \cdot \mathrm{h}^{-1}$ at gear 9 was more suitable in respect to other experimental speeds and gears.

\section{Conclusion}

According to the results, there was immediate reaction between instantaneous fuel consumption (IFC) and the forces that act on the tractor, therefore IFC is proper index for GUTD method performance and choice of suitable forward speed operation.

IFC can be applied to an alarm system programing by two ways:

Use of normal zone of IFC: the range of IFC was determined for different agricultural operations on the various soil conditions (local conditions) thus skilled drivers perform common operations (Note 1) in condition of optimum perfomance for types of common tractor. An alarm system can be designed on tractor when IFC rises over the determined range, the system alarms to tractor driver. The system configuration is easy and can be programmed for different local conditions (soil and agricultural operations).

Use of the sharp rise of IFC: it can be applied for unknown conditions, thus the forward speed and gear are gradually risen until the sharp rise in IFC will be occurred and the system alarms to tractor driver, therefore forward speed and gear before the sharp rise are chosen as suitable choice.

\section{Acknowledgements}

The authors would like to thank the Shiraz University for providing grant and necessary equipment for conducting this research.

\section{References}

ASAE Standards. (1998). ASAE S313.2 DEC94 (p. 820).

Bryan, L. (1985). Gear up and throttle down to save on fuel. Country Guide. Retrieved from http://www.pami.ca/pdfs/pami726.pdf

Campbell, D. J., \& Henshall, J. K. (2001). Bulk density. Soil and environmental analysis: Physical methods (pp. 315-348). Marcel Dekker.

Grogan, J., Morris, D. A., Searcy, S. W., \& Stout, B. A. (1987). Microcomputer-Based tractor performance monitoring and optimization system. Journal of Agricultural Engineering Research, 38(4), 227-243. http://dx.doi.org/10.1016/0021-8634(87)90091-6

Karparvarfard, S. H., \& Rahmanian-Koushkaki, H. (2015). Development of a fuel consumption equation: Test case for a tractor chisel-ploughing in a clay loam soil. Biosystems Engineering, 130, 23-33. http://dx.doi.org/10.1016/j.biosystemseng.2014.11.015

Pranava, P. K., Pandeyb, K. P., \& Tewarib, V. K. (2010). Digital wheel slipmeter for agricultural 2WD tractors. Computers and Electronics in Agriculture, 73, 188-193. http://dx.doi.org/10.1016/j.compag.2010.05.003

Raheman, H., \& Jha, S. K. (2007). Wheel slip measurement in 2WD tractor. Journal of Terramechanics, 44, 89-94. http://dx.doi.org/10.1016/j.jterra.2006.03.001

Savand, R. E. (2013). Effect of forward speed of tractor at various gear ratios on soil compaction and tire 
footprint (MS Thesis, Shiraz University, Shiraz, Iran).

Singh, C. D., \& Singh, R. C. (2011). Computerized instrumentation system for monitoring the tractor performance in the field. Journal of Terramechanics, 48, 333-338. http://dx.doi.org/10.1016/j.jterra.2011.06.007

Tewari, V. K., \& Mondal, P. (2011). Testing and performance analysis of digital fuel economizer for Tractors. British Journal of Applied Science \& Technology, 1(1), 10-15.

\section{Notes}

Note 1. Common operations: the agricultural operations are performed in local area.

\section{Copyrights}

Copyright for this article is retained by the author(s), with first publication rights granted to the journal.

This is an open-access article distributed under the terms and conditions of the Creative Commons Attribution license (http://creativecommons.org/licenses/by/3.0/). 